\title{
PKC- $\theta$ is a negative regulator of TRAIL-induced and FADD-mediated apoptotic spectrin aggregation
}

\author{
Izabela Michalczyk ${ }^{1}$, Monika Toporkiewicz ${ }^{1}$, Patrycja M. Dubielecka ${ }^{2}$, \\ Anna Chorzalska ${ }^{2}$, Aleksander F. Sikorski ${ }^{1}$ \\ ${ }^{1}$ Department of Cytobiochemistry, Faculty of Biotechnology, University of Wroclaw, Poland \\ ${ }^{2}$ Warren Alpert Medical School of Brown University, Signal Transduction Lab, Rhode Island \\ Hospital, Providence, RI, USA
}

\begin{abstract}
Introduction. During studies on chemotherapy-induced apoptosis in lymphoid cells, we noted that aggregation of spectrin occurred early in apoptosis, i.e. before activation of initiator caspase(s) and prior to exposure of phosphatidylserine (PS). We also found that protein kinase $\mathrm{C}$ theta $(\mathrm{PKC}-\theta)$ co-localized with spectrin in these aggregates. Our previously published studies indicated that in formation of early apoptotic spectrin aggregates, either PKC- $\theta$ or other apoptosis-related proteins are involved. Taking into consideration above data, we decided to test the effect of PKC- $\theta$ and Fas-associated death domain protein (FADD) on spectrin aggregation in these cells during tumor necrosis factor-related apoptosis-inducing ligand (TRAIL)-induced apoptosis.

Material and methods. For PKC- $\theta$ gene (PRKCQ) or $F A D D$ gene expression silencing in Jurkat $\mathrm{T}$ cells we used lentiviral particles containing shRNA and scrambled shRNA, respectively. Spectrin aggregates were detected by Western blotting after Triton-X 100 extraction in pellet and soluble fractions or by confocal imaging.

Results. TRAIL-induced apoptosis results in spectrin aggregation and leads to translocation and aggregation of PKC- $\theta$. We found that phorbol-myristate acetate, a PKC activator and translocation inducer, has only a small effect on spectrin aggregation. To further confirm this, we have also shown that knock down of $P R K C Q$ in Jurkat T cells accelerates the formation of TRAIL-induced spectrin aggregates. Transient overexpression of the $\beta$-spectrin $\mathrm{C}$-terminal fragment, containing multiple $\mathrm{S} / \mathrm{T}$ phosphorylation sites, potential substrate sites for PKC- $\theta$, accelerated the formation of spectrin aggregates. Silencing of downstream TRAIL receptor effector gene, $F A D D$, delayed aggregation of spectrin, but did not reduce PKC- $\theta$ localization to the plasma membrane. Conclusions. In summary, our results show for the first time involvement of spectrin aggregation in TRAIL receptor-FADD apoptotic pathway and indicate that TRAIL-induced spectrin aggregate formation is mediated by FADD and negatively regulated by PKC- $\theta$. (Folia Histochem Cytobiol. 2016, Vol. 54, No. 1, 1-13).
\end{abstract}

Key words: apoptosis; FADD; TRAIL; PKC theta; spectrin aggregation; Jurkat T cell; shRNA

\section{Introduction}

During studies on chemotherapy-induced apoptosis (fludarabine, mitoxantrone, and dexamethasone,

Correspondence address: Prof. A.F. Sikorski

Department of Cytobiochemistry

Faculty of Biotechnology

University of Wroclaw

Joliot-Curie 14a, 50-383 Wroclaw, Poland

e-mail: afsbc@ibmb.uni.wroc.pl

tel: +48713756233 regimen; FND) in non-Hodgkin Lymphoma (NHL) lymphoid cells, we noted that rearrangement of spectrin, a central structural protein of the membrane skeleton occurred. Observed aggregation of spectrin occurred early in apoptosis, before activation of initiator caspase(s) and prior to exposure of phosphatidylserine (PS). We also found that protein kinase $C$ theta $(\mathrm{PKC}-\theta)$ co-localized with spectrin in these aggregates in FND-treated Jurkat $\mathrm{T}$ cells $[1,2]$.

Spectrin is a structural protein that regulates cell mechanics [3, 4], but it has also been shown to be involved in signal transduction [5-9]. Non-erythroid 
Table 1. Antibodies used in this study

\begin{tabular}{|l|l|l|}
\hline Antibody & Working dilutions & Source \\
\hline Monoclonal rabbit anti-PKC- $\theta$ & $1: 1000(\mathrm{WB}), 1: 100(\mathrm{IF})$ & AbCam, Cambridge, UK \\
\hline Monoclonal mouse anti-spectrin & $1: 1000(\mathrm{WB}), 1: 100(\mathrm{IF})$ & Santa Cruz Biotechnology Inc. \\
\hline Monoclonal mouse anti-FADD & $1: 1000(\mathrm{WB})$ & Santa Cruz Biotechnology Inc. \\
\hline Monoclonal rabbit anti-phosphoserine/tyrosine & $1: 500(\mathrm{WB})$ & Santa Cruz Biotechnology Inc. \\
\hline Polyclonal rabbit anti-actin & $1: 5000(\mathrm{WB})$ & GeneTex Inc. \\
\hline Donkey anti-rabbit-HRP & $1: 10000(\mathrm{WB})$ & Santa Cruz Biotechnology Inc. \\
\hline Goat anti-mouse-HRP & $1: 10000(\mathrm{WB})$ & Santa Cruz Biotechnology Inc. \\
\hline Donkey anti-rabbit-Cy5 & $1: 100(\mathrm{IF})$ & Jackson ImmunoResearch Laboratories \\
\hline Goat anti-rabbit-Alexa488 & $1: 400(\mathrm{IF})$ & AbCam, Cambridge, UK \\
\hline Donkey anti-mouse-Cy5 & $1: 400(\mathrm{IF})$ & Jackson ImmunoResearch Laboratories \\
\hline
\end{tabular}

IF — immunofluorescence; WB — western blotting

spectrin $\alpha \mathrm{II} \beta \mathrm{II}$ forms a membrane skeletal network via association with adducin [10,11], actin [12, 13], and protein $4.1[14,15]$, among numerous other proteins (for a review see 3 ). This 'network' arrangement is characteristic of unstimulated cells. Various stimuli may lead to changes in the cellular distribution of spectrin, including its aggregation. Formation of aggregates was observed upon phosphorylation of adducin by PKC activated by phorbol-myristate acetate (PMA) $[16,17]$ which resulted in the dissociation of spectrin from the spectrin-actin complex [18]. Aggregation of spectrin was also shown during induced hyperthermia [19] or lymphocyte activation [20], occurring concomitantly with PKC- $\beta$ and PKC- $\theta$ activity. In these aggregates $\beta$ spectrin was found phosphorylated, and the whole process was inhibited by bisindolylmaleimide-1, the PKC inhibitor [19].

PKC- $\theta$, is a member of the novel of PKC family. It is present in a wide variety of cells, from hematopoietic cells through skeletal muscle $[22,23]$ to neurons $[24,25]$. PKC- $\theta$ plays a role in the regulation of cell migration, lymphoid cell motility [26], and signaling pathways (for review see 21), including $T$ cell activation [27] or survival [28] and activation-induced cell death (AICD) by FasL (CD95L) [29, 30]. Its role in mitosis and cell cycle regulation was also implicated $[31,32]$. Interestingly, most of these processes involve cellular relocation of PKC- $\theta$ and cytoskeletal rearrangements; however, the mechanistic details of the regulatory role of PKC- $\theta$ on cytoskeleton and membrane skeleton are not fully understood.

The previously published studies $[1,2]$ indicated that in spectrin aggregate formation during early apoptosis, either PKC- $\theta$ or other apoptosis-related proteins are involved. Taking into consideration that PKC- $\theta$ is a PKC isoform expressed at a higher level than its close homolog, PKC- $\delta$, in Jurkat T cells, we decided to test the effect of PKC- $\theta$ and Fas-associated death domain protein (FADD) on spectrin aggregation in these cells. Here, we found that PMA that is known PKC- $\theta$ activator and inducer of its translocation [33, 34], has only a small effect on tumor necrosis factor-related apoptosis-inducing ligand (TRAIL)-induced apoptotic spectrin aggregation. In Jurkat $\mathrm{T}$ cells with PKC- $\theta$ gene (PRKCQ) knock-down $(\mathrm{KnD})$ spectrin aggregate formation was accelerated. Transient overexpression of the beta-spectrin C-terminal fragment, as a potential PKC- $\theta$ substrate, accelerated formation of spectrin aggregates but delayed translocation of PKC- $\theta$ to these aggregates. Silencing of $F A D D$ gene expression delayed apoptotic aggregation of spectrin reported in the present study shed more light on the molecular mechanism of early apoptotic spectrin aggregate formation, indicating that either PKC- $\theta$ or FADD are involved in the process.

\section{Material and methods}

Antibodies. The antibodies used in this study for Western blotting and immunofluorescent staining are listed in Table 1.

Primers. The following primers were used for C-terminal fragment of spectrin conjugated to Green Fluorescent Protein (Spc-GFP) generation: FP 5' GAG CGA GAA AAA CGC TTC AGC TCC TAG G, RP 5' GAG CGA GAA AAA CGC TTC AGC TTC.

Cell cultures, apoptosis induction, and PKC activation. Jurkat $\mathrm{T}$ cells obtained from the DSMZ (German Collection of Microorganisms and Cell Cultures), were grown in RPMI 1640 medium supplemented with $10 \%$ (v/v) fetal calf serum, 
$29.2 \mathrm{mg} / \mathrm{mL}$ glutamine, $100 \mu \mathrm{g} / \mathrm{mL}$ penicillin, and $100 \mu \mathrm{g} / \mathrm{mL}$ streptomycin (all from Lonza Group, Basel, Switzerland) at $37^{\circ} \mathrm{C}, 5 \% \mathrm{CO} 2$ and $95 \%$ humidity. Cells were passaged every 2-3 days. For experiments, cells in the middle of the logarithmic growth phase (48 $\mathrm{h}$ after passage) were used. Apoptosis was induced via activation of the TRAIL-receptor pathway by adding TRAIL (recombinant protein that bind to TNFRSF10A/ /TRAILR1, TNFRSF10B/TRAILR2 to induce apoptosis, at $100 \mathrm{ng} / \mathrm{mL}$ final concentration; AbCam, Cambridge, UK) to the culture medium and with of hydrogen peroxide $(100 \mu \mathrm{M}$ final concentration, $\mathrm{POCH}$, Poland). In experiments with $\mathrm{PKC}$ activator, we used phorbol 12-myristate 13-acetate (PMA, Sigma-Aldrich, St. Louis, MO, USA) at a concentration of $100 \mathrm{nM}$.

PRKCQ /FADD gene expression silencing in Jurkat $\mathbf{T}$ cells. PRKCQ (PKC- $\theta$ ) or FADD shRNA containing lentiviral particles (Santa Cruz Biotechnology Inc., Dallas, TX, USA) were used for gene silencing. The transduction procedure was done according to the manufacturer's protocols. Lentiviral particles containing scrambled shRNA were used as a negative control for silencing of gene expression. Briefly: The suspension of lentivirus particles designed to silence $P R K C Q(\mathrm{PKC}-\theta)$ or $F A D D$ gene expression contained $1 \times 10^{6}$ infectious units of virus in $200 \mu \mathrm{L}$. Jurkat T cells (cells should be approximately $50 \%$ confluent) were incubated with the lentiviral transduction particles $(20 \mu \mathrm{L})$ in the presence of $5 \mu \mathrm{g} / \mathrm{mL}$ of polibrene (Santa Cruz Biotechnology Inc.) for $16 \mathrm{~h}$, then the medium was replaced with RPMI medium containing puromycin (Santa Cruz Biotechnology Inc.) at a final concentration of $2 \mu \mathrm{g} / \mathrm{mL}$ and cultured for additional $48 \mathrm{~h}$.

Detection of apoptosis by flow cytometry. Apoptotic cells were quantified as the percentage of cells exposing phosphatidylserine (PS). Staining of Annexin V-FITC was performed in accordance with the manufacturer's instructions (Annexin V: FITC Apoptosis Detection Kit II, BD BioScience, Franklin Lakes, NJ, USA). Stained cells were analyzed using a flow cytometer (BD FACSCalibur, with CellQuestPro software, Becton Dickinson).

Triton X-100 extraction, electrophoresis, and Western Blotting. Cellswere incubated in lysis buffer $1 \%$ Triton X-100, $100 \mathrm{mg} / \mathrm{mL}$ PMSF (phenylmethylsulfonyl fluoride) and $1 \mathrm{mM}$ EDTA, in an ice bath for $10 \mathrm{~min}$, with occasional rapid stirring. The resulting cell lysates were centrifuged (30,000 g, $4^{\circ} \mathrm{C}, 20 \mathrm{~min}$ ), and the supernatants or pellets were solubilized in a reducing reagent $(4 \times$ concentrated, $277.8 \mathrm{mM}$ Tris- $\mathrm{HCl}$, pH 6.8 sample buffer, $44.4 \%$ (v/v) glycerol, 4.4\% SDS, $0.02 \%$ bromophenol blue) and subjected to standard SDS-PAGE (12\% polyacrylamide electrophoresis gel, for 2-3 h, $30 \mathrm{~mA}$ ) and immunoblotting (16 h, $400 \mathrm{~mA})$. Band density was determined by Image J software (NIH, Bethesda, MD, USA). Presented Western blots are representative from group of biological replicates (at least three) and the data in the graphs are average of biological replicates with standard deviation (SD) bars.

Immunofluorescence. Cells were pelleted onto slides by centrifugation ( $800 \mathrm{~g}, 5 \mathrm{~min}$ ) and dried for $24 \mathrm{~h}$ at room temperature. Slides were fixed in $4 \%$ formaldehyde for $5 \mathrm{~min}$ at room temperature (RT) and permeabilized by incubation in $0.1 \%$ Triton $\mathrm{X}-100$ for $30 \mathrm{~min}$. To reduce non-specific interactions, slides were incubated for $1 \mathrm{~h}$ with $1 \%$ fetal calf serum. Then slides were incubated overnight with the appropriate dilution of each primary antibody. Afterwards slides were incubated with appropriate secondary antibodies ( $2 \mathrm{~h}, \mathrm{RT}$ ). Slides were rinsed 3 times in phosphate-buffered saline (PBS) between incubations. Appropriate negative controls were performed by omitting primary antibody. Observations were performed by using a Zeiss microscope LSM510-Meta with an Apochromat $63 \times$ objective with a numerical aperture of 1.4 (Zeiss, Jena, Germany).

Generation of C-terminal $\beta$ spectrin fragment-GFP vector. mRNA was isolated from Jurkat $\mathrm{T}$ cell line using a Titanium One Step RT-PCR Kit (Clontech, Mountain View, CA, USA). RT-PCR was performed using the appropriate primers to produce the desired 730 bp cDNA encoding a spectrin fragment consisting of aminoacid residues from 2142 to 2384 . The primers were designed to incorporate the restriction sites for HindIII and BamHI at the 5'-ends of the forward and reverse primers, respectively (all from Thermo Fisher Scientific, Inc., Waltham, MA, USA). The fragment was inserted into P-max C-Green (Lonza Group) at the HindIII and BamHI sites using T4 ligase (Thermo Fisher Scientific, Inc.). The ligation mixture was transformed into E. coli $\mathrm{DH} 5 \alpha$ bacteria by the heat-shock method: $30 \mathrm{~min}$ on ice, $90 \mathrm{sec}$ at $42^{\circ} \mathrm{C}, 2$ min on ice. Eight milliliters of SOC (super optimal catabolite repression, mixture containing yeast extract, tryptone, $\mathrm{NaCl}, \mathrm{MgCl}_{2}, \mathrm{KCl}$ ) was added and bacteria were incubated at $37^{\circ} \mathrm{C}$ for $4 \mathrm{~h}$ with shaking. Bacteria were plated on LB (Luria Bertani) agar medium containing $50 \mu \mathrm{g} / \mathrm{mL}$ kanamycin (all from Sigma-Aldrich). Positive colonies bearing reaction plasmid detected by PCR were inoculated into liquid LB medium (30 mg/mL kanamycin) to purify plasmid. Isolation of plasmid DNA was performed using a QiaPrep Spin Miniprep kit (Qiagen, Venlo, Netherlands). Transfection of Jurkat $T$ cells with plasmid DNA was performed using a commercially available electroporator, CLB-Transfection Device with CLB-Transfection Pulse optimal for Jurkat T cells (CELL 9, Lonza Group) according to the manufacturer's protocol (Cell Line Nucleofector ${ }^{\circledR}$ Kit, Lonza). Transfection efficiency was measured by GFP signal intensity using a BD FACSCalibur flow cytometer.

Statistical analysis. Statistical analysis of the results was performed using Student's t-Test considering $\mathrm{P} \leq 0.05$ or $\mathrm{P} \leq 0.01$ as significant. 


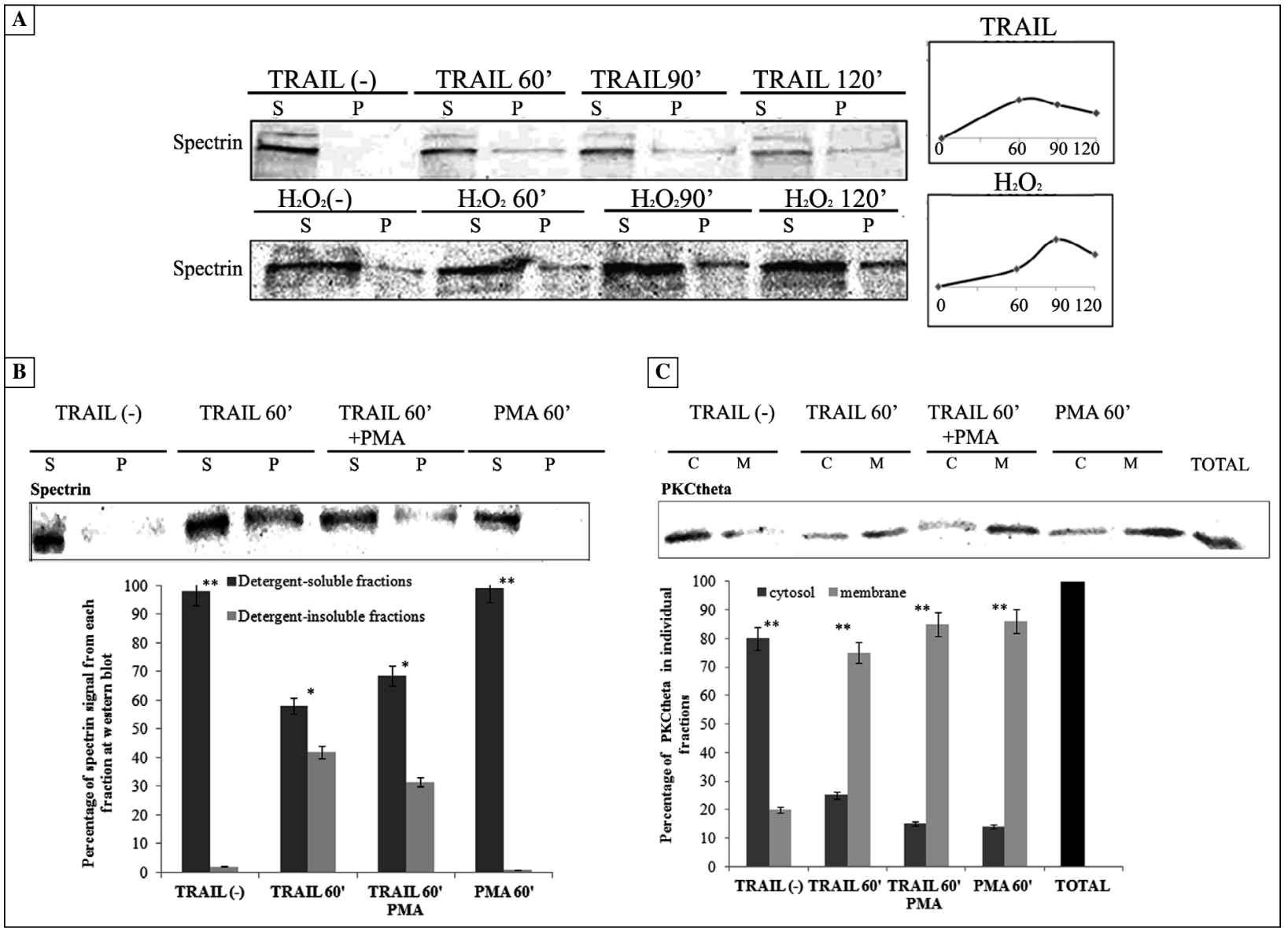

Figure 1. Effects of tumor necrosis factor-related apoptosis-inducing ligand (TRAIL) and phorbol-myristate acetate (PMA) on spectrin aggregation. A. Time course reveals that spectrin aggregation is more sensitive to TRAIL-induced $(100 \mathrm{ng} / \mathrm{mL})$ than $\mathrm{H}_{2} \mathrm{O}_{2}$-induced $(100 \mu \mathrm{M})$ apoptosis. Western blot analysis was performed using mouse anti-spectrin and developed by using appropriate secondary antibodies as detailed in Table 1. Densitometric analyses of the data (signals from control insoluble fractions are subtracted from signals from apoptotic insoluble fractions). S - supernatant, Triton X-100 soluble fraction; P - pellet, Triton X-100 insoluble fraction; B. PMA treatment does not lead to spectrin aggregation. Cells treated with TRAIL, PMA, or TRAIL and PMA (concentrations as above) for 60 min were extracted with cold $1 \%$ Triton X-100 and centrifuged at 30,000 g. Supernatant and pellet at the same protein concentrations were subjected to SDS-PAGE (12\%) electrophoresis, and transferred onto nitrocellulose. S - supernatant, Triton X-100 soluble fraction; $\mathrm{P}$ - pellet, Triton $\mathrm{X}-100$ insoluble fraction; ${ }^{*}{ }^{* *} \mathrm{P} \leq 0.05$ and $\mathrm{P} \leq 0.01$, respectively; $\mathrm{C}$. Protein kinase $\mathrm{C}$ theta (PKC- $\theta$ ) translocates to the "membrane fractions" during apoptosis induced by TRAIL (100 ng/mL) and PMA (100 nM) treatment. A simplified subcellular fractionation experiment and Western blot were performed using mouse anti-spectrin and rabbit anti-PKC- $\theta$ and developed by using appropriate secondary antibodies as detailed in Table 1 in Material and methods. Densitometric analyses show the percentage of PKC- $\theta$ in each membrane and cytosol fraction. Graph represents means of biological triplicates, with error bars being standard deviations. $\mathrm{C}$ - cytosol fraction; $\mathrm{M}$ - membrane fraction

\section{Results}

\section{TRAIL-treatment induces spectrin aggregation}

We tested whether spectrin aggregation observed during early apoptosis was induced by the extrinsic, intrinsic or both apoptotic pathways. Cells were treated with TRAIL (an activator of the extrinsic receptor-mediated apoptotic pathway) or hydrogen peroxide (an inducer of the intrinsic mitochondrial apoptotic pathway). We found that spectrin aggregates were formed during apoptosis induced by both pathways, but this process occurred faster via the TRAIL-induced extrinsic pathway (Figure 1A).
To detect spectrin and PKC- $\theta$ aggregation upon TRAIL-induced apoptosis, we analyzed presence of both proteins in Triton X-100-insoluble and soluble fractions (pellets and supernatants, respectively). As a control treatment for PKC- $\theta$ translocation we used PMA. Spectrin aggregation, observed within $60 \mathrm{~min}$ of TRAIL treatment, was significantly reduced in both TRAIL and TRAIL with PMA treatments and was not detectable upon PMA treatment only. However, the exposition of cells to PMA and TRAIL decreased the amount of spectrin present in the aggregates from $42 \%$ (TRAIL treatment only) to $31 \%$ (TRAIL and PMA treatment) (Figure 1B). 
PKC- $\theta$ translocation from cytosol to the membrane fraction was observed within $60 \mathrm{~min}$ of TRAIL, TRAIL and PMA or PMA treatment (Figure 1C). The data show that the effects of these two factors (TRAIL and/or PMA) on PKC- $\theta$ were not additive.

The obtained results indicate that PMA treatment alone induces PKC translocation but has no effect on spectrin aggregation status. In contrast to PMA, TRAIL leads to spectrin aggregation and PKC- $\theta$ translocation.

FADD plays a role as an inducer of spectrin-aggregation Because spectrin aggregates within activation of TRAIL receptor and before caspase 8 activation [2], therefore we reasoned that in the interval between of these two signals, there might be a trigger to the formation of spectrin-based apoptotic complexes. FADD is a candidate for this trigger as it acts following TRAIL-R activation, but before spectrin aggregation and caspase 8 activation [36]. In order to test this, we silenced $F A D D$ gene and evaluated effects of its KnD on TRAIL-induced spectrin aggregation. Lentiviral-based silencing resulted in a $\sim 70 \%$ reduction in the expression of $F A D D$ in Jurkat $\mathrm{T} F A D D \mathrm{KnD}$ cells (Figure 2A). Analysis of PS exposure indicated that after 320 min of TRAIL-treatment $F A D D$ KnD Jurkat $\mathrm{T}$ cells were less prone to apoptosis $(\mathrm{P} \leq 0.01)$ than the control Jurkat $T$ cells (Figure 2B). Early apoptotic spectrin aggregation in $F A D D \mathrm{KnD}$ cells, measured as the amount of spectrin in Triton X-100-insoluble fraction, was delayed (120 min) compared to control Jurkat $\mathrm{T}$ cells (60 min, Figure 2C, D). The data indicate that $F A D D$ silencing had positive effect on PKC- $\theta$ translocation, as PKC- $\theta$ was mostly present in the membrane zone or membrane fraction in $F A D D$ $\mathrm{KnD}$ cells (Figure 2D, E), and it also indicates that TRAIL-FADD signaling is involved in induction of spectrin aggregation.

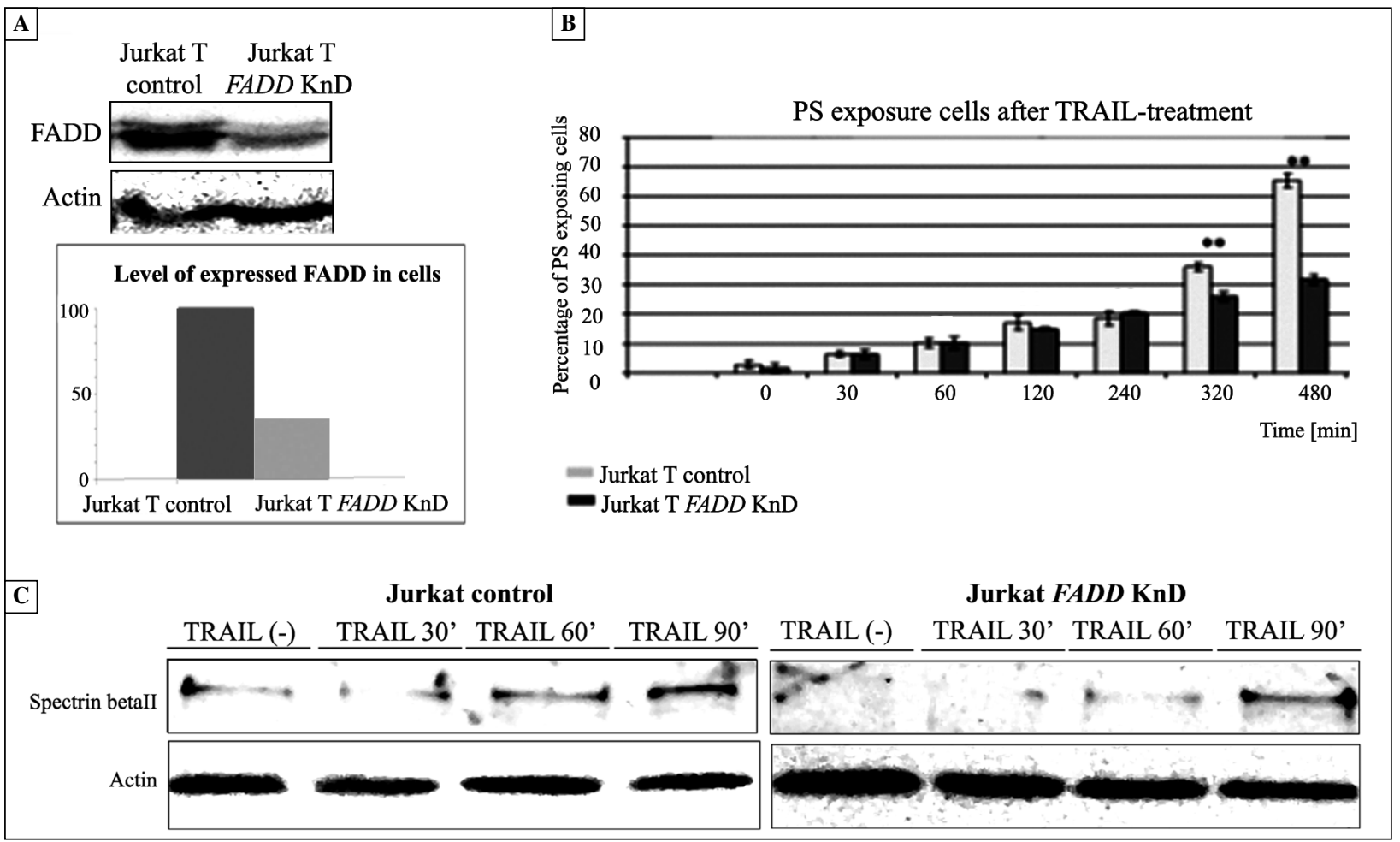

Figure 2. Aggregation of spectrin in Fas-associated death domain protein $(F A D D)$ knockdown $(\mathrm{KnD})$ Jurkat T cells upon tumor necrosis factor-related apoptosis-inducing ligand (TRAIL-induced apoptosis). A. Level of FADD protein is decreased by $70 \%$ in $F A D D \mathrm{KnD}$ cells, in comparison to control Jurkat T cells. shRNA lentiviral vector was used to establish stable FADD KnD cell-line. Level of FADD was analyzed by immunoblotting using mouse anti-FADD and rabbit anti-actin and developed by using appropriate secondary antibodies as detailed in Table 1 in Material and methods, and evaluated by densitometry; B. Progression of TRAIL-induced apoptosis in FADD KnD cells was evaluated using an Annexin V-FITC Apoptotic Detection Kit with a flow cytometer. Note a statistically significant difference in the progression of apoptosis in FADD KnD cells compared to control cells within 4 h of TRAIL treatment $(100 \mathrm{ng} / \mathrm{mL}) ; * * * \mathrm{P} \leq 0.05$ and $\mathrm{P} \leq 0.01$, respectively; $\mathbf{C}$. Spectrin aggregates were observed later (90 min of TRAIL-treatment) in FADD KnD cells than in control cells ( 60 min of TRAIL-treatment). Analysis of spectrin aggregation in FADD KnD cells was performed by immunoblot analysis of detergent-insoluble fractions using mouse anti-spectrin and mouse anti-actin and developed by using appropriate secondary antibodies as detailed in Table 1 


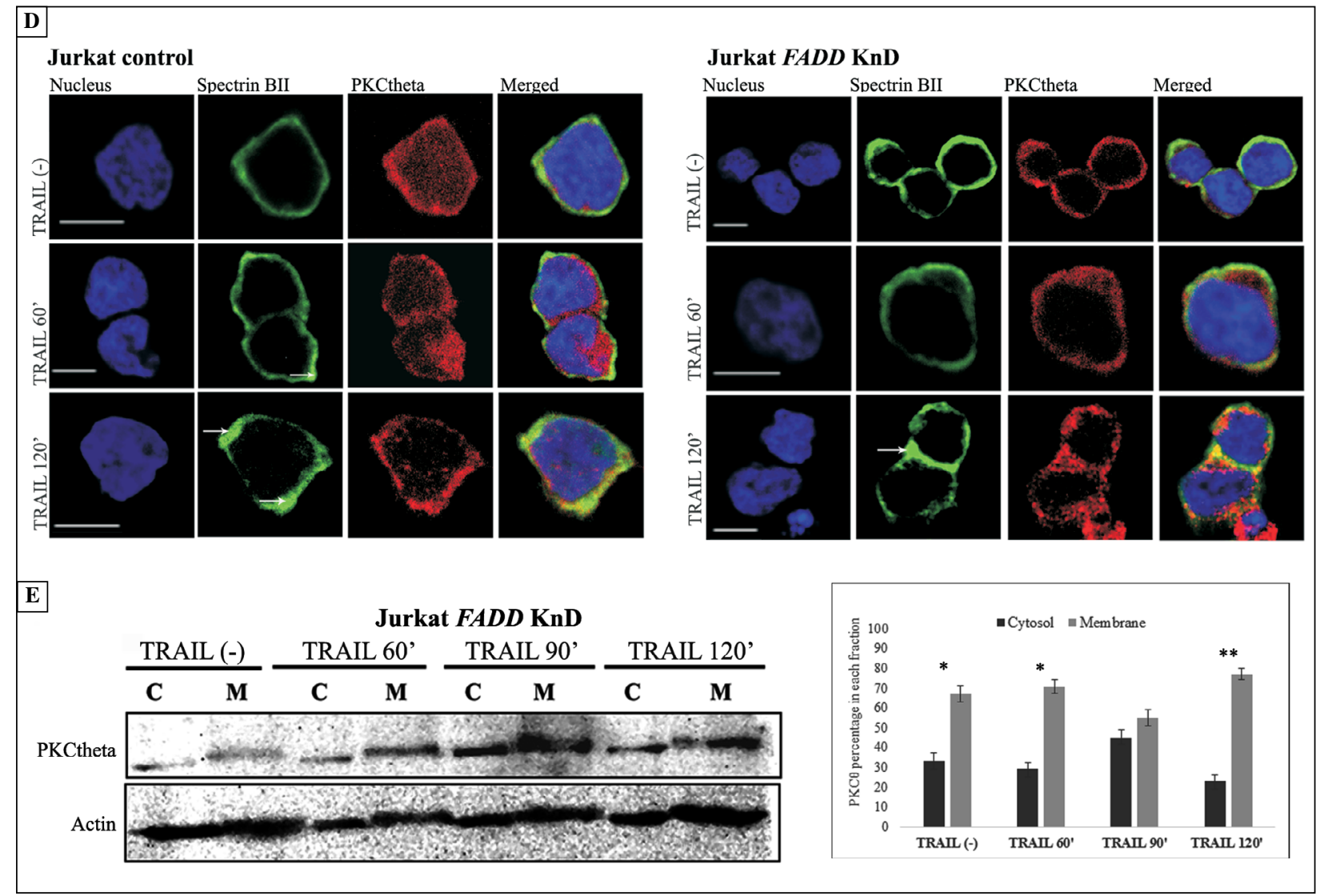

Figure 2. (cont.) Aggregation of spectrin in $F A D D$ KnD Jurkat T cells upon TRAIL-induced apoptosis. D. Dynamics of spectrin and PKC- $\theta$ aggregation in $F A D D \mathrm{KnD}$ cells compared to control Jurkat T cells. Note: delayed aggregation of spectrin (green fluorescence) in Jurkat T control and $F A D D \mathrm{KnD}$ cells upon TRAIL-induced apoptosis, compared to unstimulated Jurkat $\mathrm{T}$ control cells. A delayed translocation of protein kinases $\mathrm{C}$ theta (PKC- $\theta$ ) (red) is also seen in $F A D D \mathrm{KnD}$ cells. Blue fluorescence $=$ nuclei $(\mathrm{DAPI})$, yellow $=$ superposition of red and green fluorescence (colocalization of spectrin betaII and PKC- $\theta$ ). Immunofluorescence was performed using mouse anti-spectrin and rabbit anti-PKC- $\theta$ and developed by using appropriate secondary antibodies as detailed in Table 1 . Scale bar $5 \mu \mathrm{m}$. For details see Material and methods E. A simplified subcellular fractionation experiment and Western blot analysis shows that PKC- $\theta$ is located in the membrane, even in untreated $F A D D \mathrm{KnD}$ cells. TRAIL-induced apoptosis accelerates the level of PKC- $\theta$ in the membrane. All experimental details are presented in Material and methods. Densitometric analyses of membrane and cytosolic fractions are also presented in the right panel in section E. Graph represents means of biological triplicates, with error bars being standard deviations. $\mathrm{C}$ - cytosol fraction, $\mathrm{M}-$ membrane fraction. Western blot was performed using antibodies as above, for details see Table $1 ;{ }^{*}, * \mathrm{P} \leq 0.05$ and $\mathrm{P} \leq 0.01$, respectively

\section{Silencing of PRKCQ expression accelerates spectrin aggregation}

Based on our published results [2] and the data presented above, we postulated that PKC- $\theta$ was involved in the regulation of spectrin aggregation. To assess the role of PKC- $\theta$ in spectrin aggregation in early apoptosis, we generated $P R K C Q \mathrm{KnD}$ cells, in which PKC- $\theta$ level was reduced by more than $50 \%$ (Figure $3 \mathrm{~A}$ ). We assessed the dynamics of early apoptosis induced by TRAIL in these cells. PS exposure (as an apoptosis marker) was not significantly different from that observed in control cells up to 4 hours post TRAIL induction (Figure 3B). We observed that spectrin aggregates appeared after $10 \mathrm{~min}$ of TRAIL-R activation in PRKCQ KnD cells, but not until 1 hour in control Jurkat $\mathrm{T}$ cells (Figure 3C, D).

These data suggest that the level of PKC- $\theta$ expression may regulate spectrin aggregation under apoptotic conditions.

\section{Spectrin phosphorylation during apoptotic aggregation}

The above results suggest that $\mathrm{PKC}-\theta$ plays a role in spectrin aggregation during the early stages of apoptosis. To assess the mechanism of spectrin-aggregate formation, we tested whether PKC- $\theta$ triggers this process by affecting spectrin phosphorylation status. By Western blotting and probing with an antibody against phosphoserine/phosphothreonine residues, 


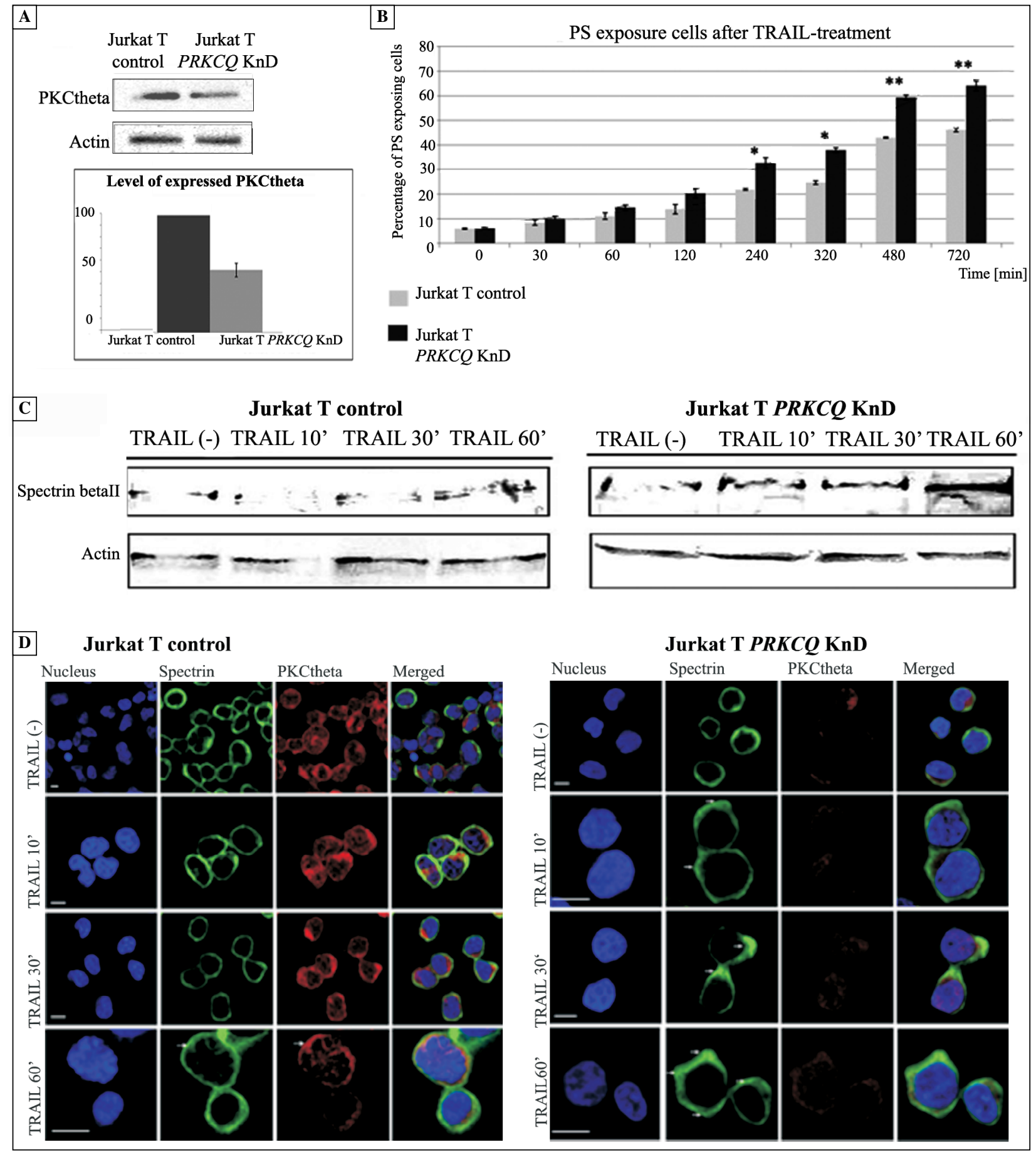

Figure 3. Protein kinase $\mathrm{C}$ theta (PKC- $\theta$ ) down-regulates spectrin aggregation in Jurkat $\mathrm{T}$ cells upon tumor necrosis factor-related apoptosis-inducing ligand (TRAIL-induced apoptosis). A. Level of PKC- $\theta$ is decreased by $50 \%$ in PRKCQ (PKC- $\theta$ gene) knockdown $(\mathrm{KnD})$ cells in comparison to control Jurkat T cells. Level of PKC- $\theta$ was analyzed by immunoblot (antibodies used: rabbit anti-PKC- $\theta$ and rabbit anti-actin, details in Table 1) and evaluated by densitometry; B. Progression of apoptosis in PRKCQ KnD cells was evaluated as described in Figure 2 legend. Note a significant difference in the progression of apoptosis in $P R K C Q \mathrm{KnD}$ cells, compared to control cells, appears within $4 \mathrm{~h}$ of TRAIL treatment $(100 \mathrm{ng} / \mathrm{mL}) ;{ }^{*}, * * \mathrm{P} \leq 0.05$ and $\mathrm{P} \leq 0.01$, respectively; $\mathbf{C}$. Insoluble spectrin was observed as soon as $10 \mathrm{~min}$ of TRAIL-treatment in PRKCQ KnD cells. Analysis of the spectrin aggregation process in early apoptotic cells in immunoblot analysis of detergent-insoluble fractions following TRAIL-induced apoptosis at 10, 30 and 60 minutes. A Western blot was performed using mouse anti-spectrin and rabbit anti-actin and developed by using appropriate secondary antibodies as detailed in Table 1; D. Dynamics of the spectrin aggregation process in PRKCQ KnD cells, compared to control Jurkat T cells. Localization of spectrin (green) and protein kinase PKC- $\theta$ (red) in control and PRKCQ KnD cells of TRAIL-induced apoptosis, compared to noninduced Jurkat $\mathrm{T}$ control cells, shows that spectrin aggregates faster in PRKCQ KnD cells. Scale bar $10 \mu \mathrm{m}$ 


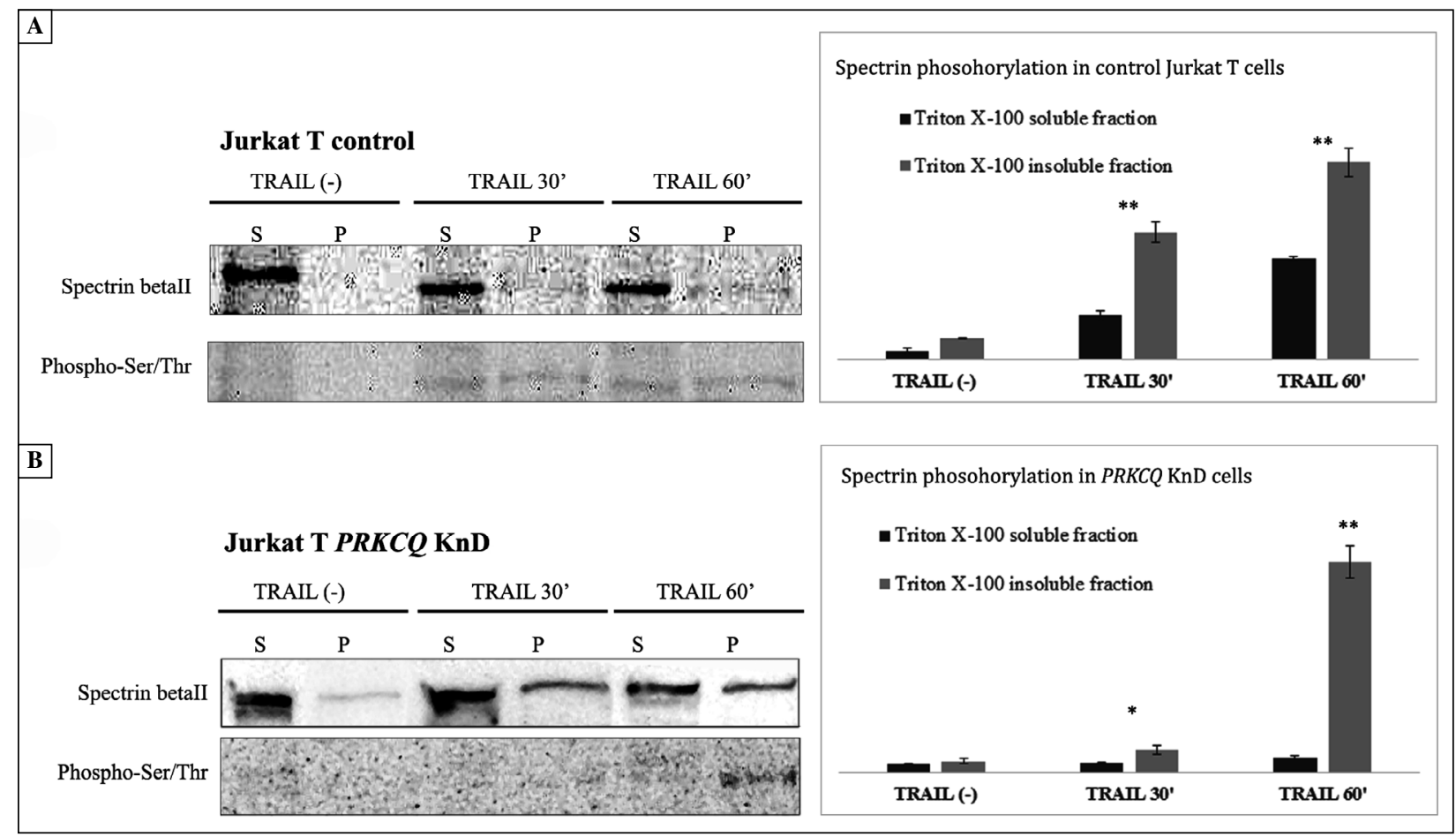

Figure 4. Spectrin phosphorylation upon apoptosis induced by tumor necrosis factor-related apoptosis-inducing ligand (TRAIL). A. Western blot analysis of detergent-soluble and insoluble fractions isolated from control Jurkat T cells within 30 and 60 min post-induction indicate phosphorylation of spectrin on $\mathrm{S} / \mathrm{T}$ residues in the same fractions as was detected immunoblotting with mouse anti-spectrin and rabbit anti-phosphoserine/threonine antibodies, as described in Table 1; B. Western blot analysis of detergent-soluble (S) and insoluble (P) fractions isolated from PRKCQ (PKC- $\theta$ gene) knockdown $(\mathrm{KnD})$ Jurkat $\mathrm{T}$ cells after the same as above time intervals indicate only the appearance of phosphospectrin in a detergent-insoluble fraction of spectrin within $60 \mathrm{~min}$ of TRAIL-treatment, even though aggregation is detectable sooner (30 min of apoptosis induced by TRAIL). S - supernatant, P - pellet. Graph represents means of biological triplicates, with error bars being standard deviations; *** $\mathrm{P} \leq 0.05$ and $\mathrm{P} \leq 0.01$

we found that spectrin became phosphorylated within 30 min of TRAIL-treatment in control Jurkat $\mathrm{T}$ cells, and phosphorylated spectrin was found both in the detergent-soluble (S) and detergent-insoluble fractions (P) (Figure 4A). Phosphorylated spectrin constituted a higher proportion of detergent-insoluble spectrin than of detergent-soluble spectrin (Figure 4A). In contrast, detergent-soluble spectrin was not phosphorylated in the PRKCQ KnD cells (Figure 4B). In the detergent-insoluble fraction, phosphorylated spectrin was only observed within $60 \mathrm{~min}$ of apoptosis induced by TRAIL. This confirms the effect of PKC- $\theta$ signaling on early apoptotic spectrin-aggregate formation but also indicates a lack of a causative role of phosphorylation on spectrin aggregates formation.

\section{Overexpression of the carboxyl-terminal fragment of spectrin $\beta I I$ affects endogenous spectrin aggregation and PKC- $\theta$ translocation}

According to the NetPhosph (http://www.cbs.dtu. $\mathrm{dk} /$ services/NetPhos/) or UniProtKB (http://www. uniprot.org/), two serine residues, S2171 and S2359, in the C-terminal fragment of $\beta$ II spectrin can be phosphorylated (Figure 5A). To determine whether an excess of this spectrin fragment would affect endogenous spectrin aggregation through its potential competition for phosphorylation on $\mathrm{S} / \mathrm{T}$ residues, the GFP-tagged C-terminal fragment of spectrin $\beta$ II (residues 2142-2384) was expressed in Jurkat T cells. Within TRAIL induction of apoptosis, progress of spectrin aggregation was evaluated in these cells and compared to control cells. We found that, after $30 \mathrm{~min}$ of TRAIL-treatment, endogenous spectrin aggregates were formed in cells overexpressing the spectrin $\beta \mathrm{II}$ fragment, whereas aggregates were absent at this time in control cells (Figure 5B). Within $30 \mathrm{~min}$ of apoptosis in cells overexpressing spectrin fragment, PKC- $\theta$ was localized mostly in cytosol, while in non-transfected cells PKC- $\theta$ was present in cytosol and cell membrane. This difference was not seen within $60 \mathrm{~min}$ of apoptosis (Figure 6). These data suggest that the $\mathrm{C}$-terminal fragment of spectrin can act as a substrate or, more possibly, as a site of interactions between spectrin and PKC- $\theta$. 


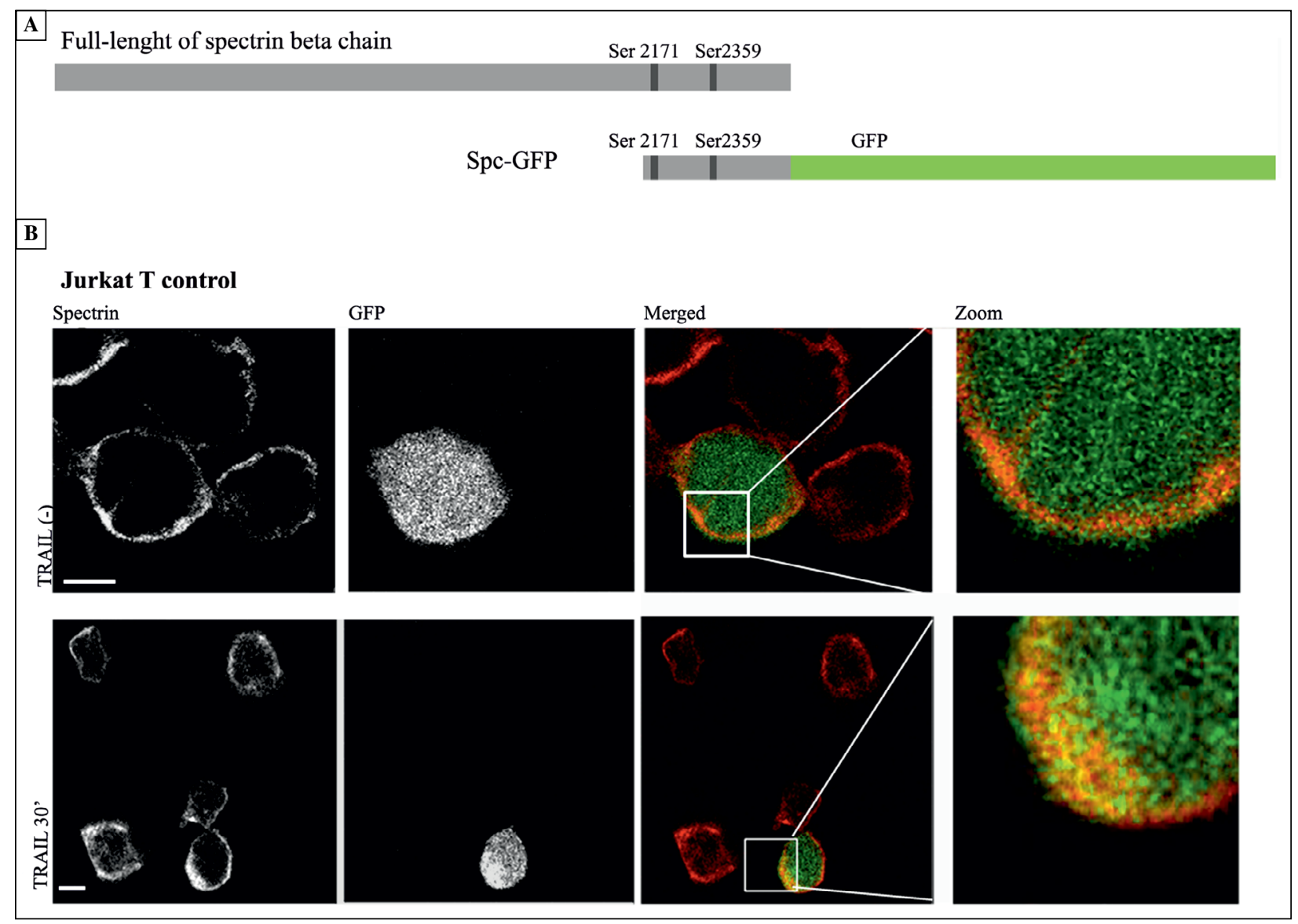

Figure 5. Overexpressed spectrin fragment accelerates aggregation of endogenous spectrin upon tumor necrosis factor-related apoptosis-inducing ligand (TRAIL-induced apoptosis) in Jurkat T cells. A. $\beta$ II spectrin fragment (2142-2384): Spc-GFP, was cloned into a GFP-tagged construct (see Material and methods section); B. Endogenous spectrin (labeled in red on merged images, antibodies used mouse anti-spectrin and developed by using appropriate secondary antibodies as detailed in Table 1 accumulates below the cell membrane within just $30 \mathrm{~min}$ of TRAIL-treatment $(100 \mathrm{ng} / \mathrm{mL})$. Compared to untransfected cells, the overexpressed fragment of spectrin accelerates aggregation of endogenous spectrin. Scale bar $10 \mu \mathrm{m}$

\section{Discussion}

The phenomenon of aggregation of spectrin, the cell membrane skeletal protein, during early apoptosis induced by a range of cytostatic drugs including fludarabine, mitoxantrone, and dexamethasone was reported a decade ago [1]. Further studies showed that spectrin aggregate formation is a hallmark of early apoptosis $[2,13]$, with the data pointing to a regulatory role for PKC $-\theta$ in this process. Cytostatic drugs are known to activate both extrinsic and intrinsic apoptotic pathways. Our data show that spectrin is more sensitive to the extrinsic pathway of apoptosis induction via TRAIL. Recombinant protein used here binds to TNFRSF10A/ /TRAILR1, TNFRSF10B/TRAILR2 to induce apoptosis (according to the manufacturer). The current study assessed the roles of PKC- $\theta$ and FADD in early apoptotic spectrin aggregation induced by TRAIL.

We compared the occurrence and timing of several events associated with apoptotic spectrin aggregation in intact Jurkat $\mathrm{T}$ and $P R K C Q$ and $F A D D \mathrm{KnD}$ cell lines. Our findings are summarized in Figure 7. In control cells, spectrin aggregates within $60 \mathrm{~min}$ of TRAIL-induced apoptosis. Spectrin aggregation is preceded by PKC- $\theta$ translocation, which occurs only within $30 \mathrm{~min}$ of apoptosis. Caspase 8 activation occurs after spectrin aggregation, and is followed by PS exposure. In $P R K C Q \mathrm{KnD}$ cells, accelerated spectrin aggregation is observed, occurring within $10 \mathrm{~min}$ of TRAIL-treatment. This is followed by caspase 8 activation and PS exposure as in control cells. In $F A D D \mathrm{KnD}$ cells, PKC- $\theta$ is present in the cell membrane before TRAIL-induced apoptosis, but aggregation of spectrin is not seen until 120 min of TRAIL-treatment. PS exposure is not seen until 720 min of TRAIL-treatment. Therefore, based on these observations, we conclude that PKC- $\theta$ is a negative regulator of TRAIL-induced and FADD mediated spectrin aggregation.

Spectrin began forming apoptotic aggregates approximately within 60 min of induction, which suggests 


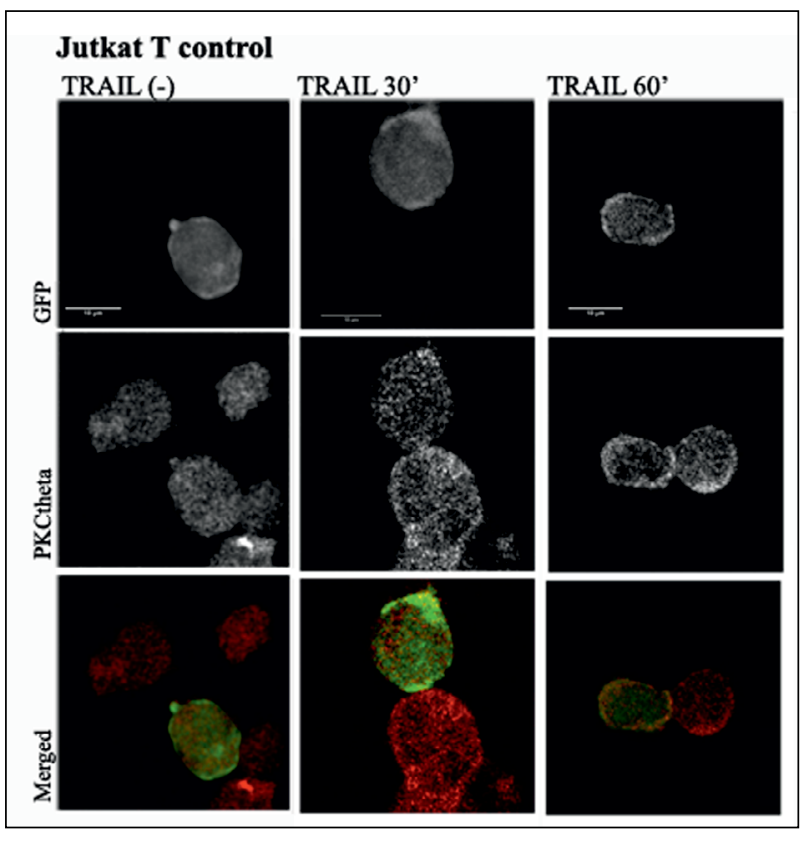

Figure 6. Effect of overexpressed spectrin fragment on protein kinase $\mathrm{C}$ theta (PKC- $\theta$ ) translocation under apoptotic conditions. In cells with overexpressed spectrin (labeled in green, antibodies used rabbit anti-PKC- $\theta$ and developed by using appropriate secondary antibodies as detailed in Table 1) delayed PKC- $\theta$ translocation from cytosol to the cell membrane of $30 \mathrm{~min}$ of tumor necrosis factor-related apoptosis-inducing ligand (TRAIL) treatment $(100 \mathrm{ng} / \mathrm{mL})$ can be observed. Within $60 \mathrm{~min}$ of apoptosis induced by TRAIL, PKC- $\theta$ is observed in the cell membrane in both cell types. Spc-GFP, labeled in green, PKC- $\theta$ labeled in red. Scale bar $10 \mu \mathrm{m}$

that the translocation/activation of PKC- $\theta$ induces aggregation of spectrin. However, we found that treatment with PMA, which induces PKC- $\theta$ activation and translocation to membrane [38], did not result in accelerated spectrin aggregation. Thus, we conclude that PKC- $\theta$ translocation/activation connected with TRAIL treatment can be a direct inducer or mediator of spectrin aggregation. Our results suggest that rather the presence of PKC- $\theta$ and not its translocation/ /activation status in the membrane can affect apoptosis-induced formation of spectrin aggregates.

In PKC- $\theta$-deficient $T$ cells Fas-induced activation of apoptotic molecules such as caspase-8, caspase-3, and Bid was not efficient and delayed apoptosis and PKC- $\theta$ deficient T cells were resistant to apoptosis [29]. The role of PKC- $\theta$ activity in regulation of apoptosis is, however, not clear and some reports show that pharmacological inhibition of PKC- $\theta$ promoted Fas-mediated apoptosis [28]. In our PKC- $\theta$-deficient model in Jurkat T, PRKCQ KnD cells, we observed increased sensitivity to the apoptotic factor, TRAIL, with accelerated spectrin aggregation, which is in agreement with our previous studies [2], but we have to remember that the effect of PKC- $\theta$ pharmacological inhibition in HL60 cells resulted in opposite effect, i.e. PS exposure and spectrin aggregation was visibly slowed down [2], therefore the effect of PKC- $\theta$ could be cell-line specific. In the same studies it was shown that formation of spectrin aggregates during early apoptosis involves PKC- $\theta$ and that the inhibition of PKC- $\theta$ by its pseudosubstrate peptide increases spectrin aggregation during the initial hours of apoptosis [2]. With these findings and our results on $P R K C Q \mathrm{KnD}$ the role of $\mathrm{PKC}-\theta$ on spectrin aggregation is clearly demonstrable, but there is an important outstanding question as to how $\mathrm{PKC}-\theta$ regulates spectrin aggregation. The data presented here indicate that the translocation/activation of PKC- $\theta$ does not lead to spectrin aggregation. $\mathrm{PKC}-\theta$ is known to re-organize the cytoskeleton through phosphorylation of its components, such as adducin [39, 40]. Phosphorylation of adducin inhibits actin-capping and maintains the ability of actin to recruit spectrin attachment to actin filaments, which leads to cytoskeletal reorganization. There is no direct evidence that spectrin is a substrate for PKC- $\theta$, but spectrin can be phosphorylated, and in its phosphorylated state affects synaptic remodeling, receptor-mediated endocytosis, apoptosis, stability of the cell membrane skeleton and the response of the renal epithelial cell to ischemic injury [30, 40-42]. Formation of spectrin aggregates in mouse lymphocytes after induction of fever-like whole body hyperthermia (WBH) was shown to involve PKC- $\theta$ and $\mathrm{PKC} \beta$, which were found in aggregates after 12 hours of WBH [19]. In these aggregates, $\beta$-spectrin was confirmed to be phosphorylated, and the process could be inhibited by the PKC inhibitor, bisindolylmaleimide. It was also showed that PKC- $\theta$ associated with spectrin mediates either the reorganization of the spectrin-based skeleton and/or phosphorylates specific nearby targets that are involved in apoptosis [19]. In our study, aggregated spectrin was also phosphorylated, but its phosphorylation is not crucial for spectrin-PKC- $\theta$ aggregation. In PRKCQ KnD cells, non-phosphorylated spectrin aggregated rapidly.

The fact that spectrin is a protein that can be phosphorylated, along with the observed presence of PKC- $\theta$ in apoptotic complexes, prompted us to assess the interaction between the GFP-conjugated C-terminal $\beta$ II spectrin fragment (GFP-Spc) and PKC- $\theta$. Overexpression of the GFP-Spc fragment resulted in faster aggregation of endogenous spectrin, and delayed translocation of PKC- $\theta$ to the membrane. These differences in PKC- $\theta$ localization were not seen during later stages of the apoptotic process. We conclude that the presence of PKC- $\theta$ in the membrane can delay spectrin aggregate formation, although the role of phosphorylation remains to be fully elucidated. It is possible that this part of spectrin 


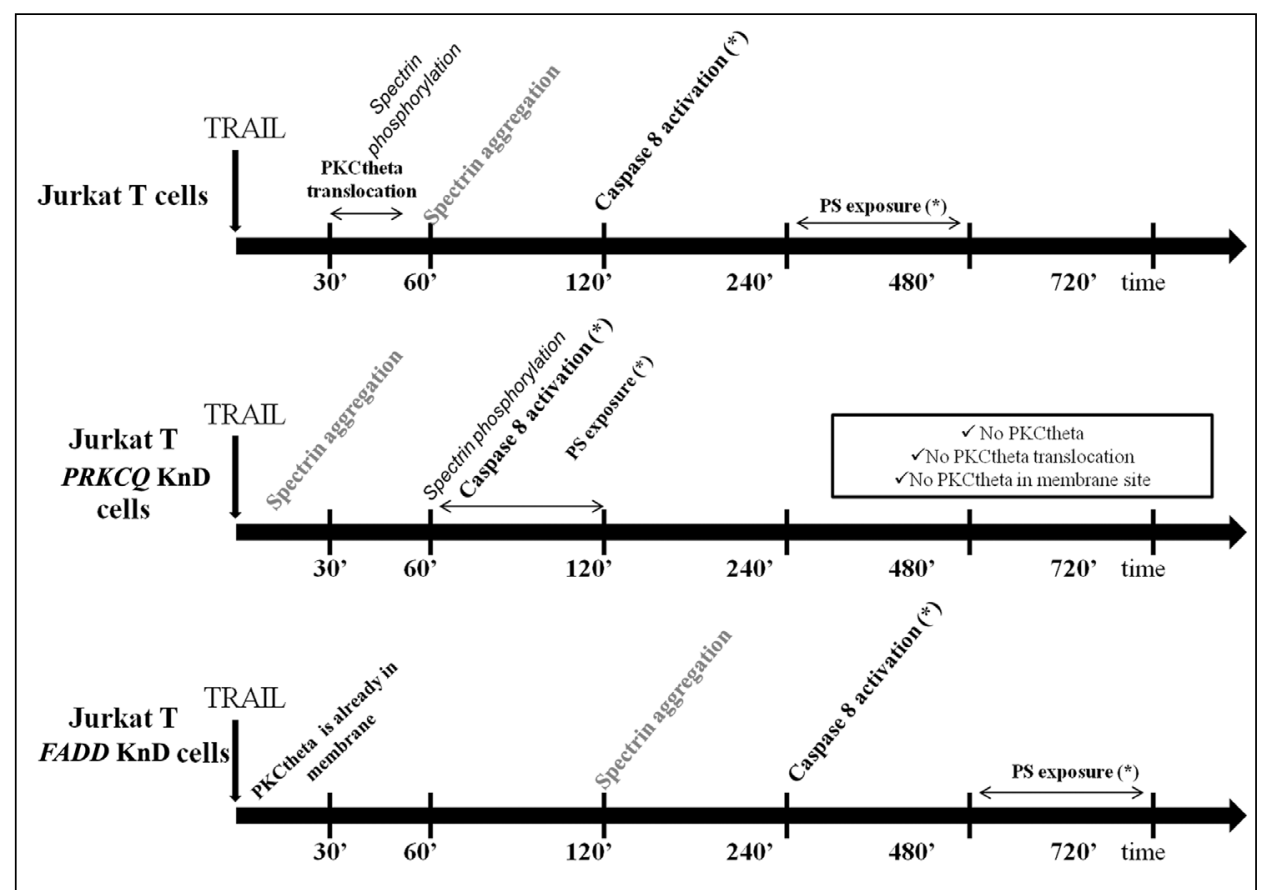

Figure 7. Sequence of events within tumor necrosis factor-related apoptosis-inducing ligand (TRAIL-induced apoptosis) in three cell lines: Jurkat T control, Jurkat T PRKCQ (PKC- $\theta$ gene) knockdown (KnD) and Jurkat T Fas-associated death domain protein $(F A D D)$. In control cells spectrin aggregates within $60 \mathrm{~min}$ of TRAIL-induced apoptosis, preceding protein kinase $\mathrm{C}$ theta (PKC- $\theta$ ) translocation (30 min of apoptosis). Within spectrin aggregation caspase 8 activation takes place, and then phosphatidyleserine (PS) exposure occurs. In PRKCQ KnD cell line, an accleleration of spectrin aggregation is observed within 10 min of TRAIL treatment, then, as in control cells, caspase 8 activation and PS exposure take place. In control cells PKC- $\theta$ translocates to the membrane fraction upon TRAIL induction of apoptosis. In cells with lower expression of $F A D D$, spectrin aggregates later, compared to control cells, but PKC- $\theta$ is already present in the cell membrane even before TRAIL-induced apoptosis. $\left({ }^{*}\right)$ assumed time where more than $30 \%$ of cells presented active caspase 8 or in other way, $30 \%$ or more cells present exposed PS

molecule is responsible for its interaction with $\mathrm{PKC}-\theta$ and phosphorylation of other skeletal or regulatory components plays a role in this process.

Understanding the molecular mechanism(s) governing spectrin aggregation will help to elucidate the role of spectrin in the early stage of apoptosis. This additional knowledge regarding the regulation of apoptosis is likely to be relevant to studies of apoptosis in cancer cells. Our results suggest that PKC- $\theta$ plays a protective 'structural-adapter' function in spectrin-aggregation, whereas FADD is a spectrin-aggregation inducer.

\section{Acknowledgements}

The authors thank Dr. Michal Grzybek for his support and useful discussions. The authors thank Dr. John Blenis (Department of Cell Biology, Harvard Medical School, Boston) for initial providing Jurkat T FADD KO cells. This work was supported by grants from University of Wroclaw (Competition for conducting research, contributing to the development of young researchers and $\mathrm{PhD}$ students of Faculty of Biotechnology, I/2012 and II/2013).

\section{References}

1. Dubielecka PM, Jazwiec B, Potoczek S et al. Changes in spectrin organisation in leukaemic and lymphoid cells upon chemotherapy. Biochem Pharmacol. 2005;69:73-85. doi: 10.1016/j.bcp.2004.08.031.

2. Dubielecka PM, Grzybek M, Kolondra A et al. Aggregation of spectrin and PKCtheta is an early hallmark of fludarabine/ /mitoxantrone/dexamethasone-induced apoptosis in Jurkat T and HL60 cells. Mol Cell Biochem. 2010;339:63-77. doi: 10.1007/s11010-009-0370-4.

3. Machnicka B, Czogalla A, Hryniewicz-Jankowska A et al. Spectrins: A structural platform for stabilization and activation of membrane channels, receptors and transporters. Biochim Biophys Acta. 2014;1838:620-634. doi: 10.1016/j. bbamem.2013.05.002.

4. Manno S, Takakuwa Y, Nagao K, Mohandas N. Modulation of erythrocyte membrane mechanical function by beta-spectrin phosphorylation and dephosphorylation. J Biol Chem. 1995;270:5659-5665. PMID: 7890688.

5. Machnicka B, Grochowalska R, Boguslawska DM, Sikorski AF, Lecomte MC. Spectrin-based skeleton as an actor in cell signaling. Cell Mol Life Sci. 2012;69:191-201. doi: 10.1007/ s00018-011-0804-5.

6. Tang Y, Katuri V, Dillner A, Mishra B, Deng CX, Mishra L. Disruption of transforming growth factor-beta signaling in ELF beta-spectrin-deficient mice. Science. 2003;299:574-577. doi: $10.1126 /$ science.1075994.

7. Bialkowska K, Saido TC, Fox JE. SH3 domain of spectrin participates in the activation of Rac in specialized calpain- 
-induced integrin signaling complexes.J Cell Sci. 2005;118:381-395. doi: 10.1242/jcs.01625.

8. Musacchio A, Gibson T, Rice P, Thompson J, Saraste M. The PH domain: a common piece in the structural patchwork of signalling proteins. Trends Biochem Sci. 1993;18:343-348. PMID: 8236453.

9. Wong KK, Li W, An Y et al. Beta-spectrin regulates the hippo signaling pathway and modulates the basal actin network. J Biol Chem. 2015;290:6397-6407. doi: 10.1074/jbc. M114.629493.

10. Li X, Matsuoka Y, Bennett V. Adducin preferentially recruits spectrin to the fast growing ends of actin filaments in a complex requiring the MARCKS-related domain and a newly defined oligomerization domain. J Biol Chem. 1998;273:19329-19338. PMID: 9668123.

11. Wu J, Masci PP, Chen C, Chen J, Lavin MF, Zhao KN. Beta-adducin siRNA disruption of the spectrin-based cytoskeleton in differentiating keratinocytes prevented by calcium acting through calmodulin/epidermal growth factor receptor/ /cadherin pathway. Cell Signal. 2015;27:15-25. doi: 10.1016/ /j.cellsig.2014.10.001.

12. Koshino I, Mohandas N, Takakuwa Y. Identification of a novel role for dematin in regulating red cell membrane function by modulating spectrin-actin interaction. $J$ Biol Chem. 2012;287:35244-35250. doi: 10.1074/jbc.M111.305441.

13. Toporkiewicz M, Grzybek M, Meissner J et al. Release of an $\sim 55 \mathrm{kDa}$ fragment containing the actin-binding domain of beta-spectrin by caspase- 8 during FND-induced apoptosis depends on the presence of protein 4.1. Arch Biochem Biophys. 2013;535:205-213. doi: 10.1016/j.abb.2013.03.009.

14. Shartava A, Monteiro CA, Bencsath FA et al. A posttranslational modification of beta-actin contributes to the slow dissociation of the spectrin-protein 4.1-actin complex of irreversibly sickled cells. J Cell Biol. 1995;128:805-818. PMID: 7876306.

15. Zhang DQ, Wang YP, Wang WH et al. Interaction between protein 4.1R and spectrin heterodimers. Mol Med Rep. 2011;4:651-654. doi: 10.3892/mmr.2011.470.

16. Miyauchi JT, Piermarini PM, Yang JD, Gilligan DM, Beyenbach KW. Roles of PKC and phospho-adducin in transepithelial fluid secretion by Malpighian tubules of the yellow fever mosquito. Tissue Barriers. 2013;1. doi: 10.4161/ /tisb.23120.

17. Gilligan DM, Sarid R, Weese J. Adducin in platelets: activation-induced phosphorylation by PKC and proteolysis by calpain. Blood. 2002;99:2418-2426. PMID: 11895774.

18. Barkalow KL, Italiano JE Jr, Chou DE, Matsuoka Y, Bennett $\mathrm{V}$, Hartwig JH. Alpha-adducin dissociates from F-actin and spectrin during platelet activation. J Cell Biol. 2003;161:557-570. doi: 10.1083/jcb.200211122.

19. Wang XY, Ostberg JR, Repasky EA. Effect of fever-like whole-body hyperthermia on lymphocyte spectrin distribution, protein kinase $\mathrm{C}$ activity, and uropod formation. J Immunol. 1999;162:3378-3387. PMID: 10092792.

20. Gregorio CC, Kubo RT, Bankert RB, Repasky EA. Translocation of spectrin and protein kinase $\mathrm{C}$ to a cytoplasmic aggregate upon lymphocyte activation. Proc Natl Acad Sci USA. 1992;89:4947-4951. PMID: 1375753.

21. Michalczyk I, Sikorski AF, Kotula L, Junghans RP, Dubielecka PM. The emerging role of protein kinase Ctheta in cytoskeletal signaling. J Leukoc Biol. 2013;93:319-327. doi: 10.1189/jlb.0812371.

22. Osada S, Mizuno K, Saido TC, Suzuki K, Kuroki T, Ohno S. A new member of the protein kinase $\mathrm{C}$ family, nPKC theta, predominantly expressed in skeletal muscle. Mol Cell Biol. 1992;12:3930-3938. PMID: 1508194.
23. Wazir R, Luo DY, Dai Y, Yue X, Tian Y, Wang KJ. Expression and proliferation profiles of PKC, JNK and p38MAPK in physiologically stretched human bladder smooth muscle cells. Biochem Biophys Res Commun. 2013;438:479-482. doi: 10.1016/j.bbrc.2013.07.115.

24. Hilgenberg L, Miles K. Developmental regulation of a protein kinase $\mathrm{C}$ isoform localized in the neuromuscular junction. J Cell Sci. 1995;108:51-61. PMID: 7738116.

25. Kempsell AT, Fieber LA. Age-related deficits in synaptic plasticity rescued by activating PKA or PKC in sensory neurons of Aplysia californica. Front Aging Neurosci. 2015;7:173. doi: 10.3389/fnagi.2015.00173.

26. Shahabi NA, McAllen K, Sharp BM. Stromal cell-derived factor 1-alpha (SDF)-induced human $\mathrm{T}$ cell chemotaxis becomes phosphoinositide 3-kinase (PI3K)-independent: role of PKC-theta. J Leukoc Biol. 2008;83:663-671. doi: 10.1189/ /jlb.0607420.

27. Monks CR, Kupfer H, Tamir I, Barlow A, Kupfer A. Selective modulation of protein kinase $\mathrm{C}$-theta during T-cell activation. Nature. 1997;385:83-86. PMID: 8985252.

28. Villalba M, Bushway P, Altman A. Protein kinase C-theta mediates a selective $T$ cell survival signal via phosphorylation of BAD. J Immunol. 2001;166:5955-5963. PMID: 11342610.

29. Manicassamy S, Sun Z. The critical role of protein kinase C-theta in Fas/Fas ligand-mediated apoptosis. J Immunol. 2007;178:312-319. doi: 10.4049/jimmunol.178.1.312.

30. Malewicz M, Zeller N, Yilmaz ZB, Weih F. NF kappa B controls the balance between Fas and tumor necrosis factor cell death pathways during $\mathrm{T}$ cell receptor-induced apoptosis via the expression of its target gene A20.J Biol Chem. 2003;278:32825-32833. doi: 10.1074/jbc.M304000200.

31. Passalacqua M, Patrone M, Sparatore B, Melloni E, Pontremoli S. Protein kinase C-theta is specifically localized on centrosomes and kinetochores in mitotic cells. Biochem J. 1999;337:113-118. PMID: 9854032.

32. Gonnella R, Granato M, Farina A, Santarelli R, Faggioni A, Cirone M. PKC theta and p38 MAPK activate the EBV lytic cycle through autophagy induction. Biochim Biophys Acta. 2015;1853:1586-1595. doi: 10.1016/j.bbamcr.2015.03.011.

33. Bi K, Tanaka Y, Coudronniere N et al. Antigen-induced translocation of $\mathrm{PKC}$-theta to membrane rafts is required for $\mathrm{T}$ cell activation. Nat Immunol. 2001;2:556-563. PMID: 11376344.

34. Villalba M, Bi K, Hu J et al. Translocation of PKC[theta] in $\mathrm{T}$ cells is mediated by a nonconventional, PI3-K- and Vav-dependent pathway, but does not absolutely require phospholipase C.J Cell Biol. 2002;157:253-263. doi: 10.1083/ /jcb.200201097.

35. Gomez-Angelats M, Bortner CD, Cidlowski JA. Protein kinase C (PKC) inhibits fas receptor-induced apoptosis through modulation of the loss of $\mathrm{K}+$ and cell shrinkage. A role for PKC upstream of caspases. J Biol Chem. 2000;275:19609-19619. PMID: 10867019.

36. Hu Q, Cui X, Tao L, Xiu L, Wang T, Wang X. Staphylococcus aureus induces apoptosis in primary bovine mammary epithelial cells through Fas-FADD death receptor-linked caspase-8 signaling. DNA Cell Biol. 2014;33:388-397. doi: 10.1089/dna.2013.2195.

37. Huang SC, Tsai HF, Tzeng HT, Liao HJ, Hsu PN. Lipid raft assembly and Lck recruitment in TRAIL costimulation mediates NF-kappaB activation and T cell proliferation. JImmunol. 2011;186:931-939. doi: 10.4049/jimmunol.1001092.

38. Freeley M, Volkov Y, Kelleher D, Long A. Stimulus-induced phosphorylation of PKC theta at the C-terminal hydrophobic-motif in human T lymphocytes. Biochem Biophys Res Commun. 2005;334:619-630. doi: 10.1016/j.bbrc.2005.06.136. 
39. Matsuoka Y, Li X, Bennett V. Adducin is an in vivo substrate for protein kinase C: phosphorylation in the MARCKS-related domain inhibits activity in promoting spectrin-actin complexes and occurs in many cells, including dendritic spines of neurons. J Cell Biol. 1998;142:485-497. PMID: 9679146.

40. Bretscher A. Rapid phosphorylation and reorganization of ezrin and spectrin accompany morphological changes induced in A-431 cells by epidermal growth factor. J Cell Biol. 1989;108:921-930. PMID: 2646308.
41. Perrotta S, del Giudice EM, Iolascon A et al. Reversible erythrocyte skeleton destabilization is modulated by beta-spectrin phosphorylation in childhood leukemia. Leukemia. 2001;15:440-444. PMID: 11237068.

42. Roses AD, Herbstreith M, Metcalf B, Appel SH. Increased phosphorylated components of erythrocyte membrane spectrin band II with reference to Duchenne muscular dystrophy. J Neurol Sci. 1976;30:167-178. PMID: 10352.

Submitted: 3 December, 2015 Accepted after reviews: 5 April, 2016 Available as AoP: 18 April, 2016 